\title{
Sex Differences in Cerebral Edema after Experimental Traumatic Brain Injury
}

Heather M Minchew ${ }^{1}$, Sarah K Christian ${ }^{2}$, Paul Keselman ${ }^{3}$, Jinxiang $\mathrm{Hu}^{4}$, Brian T Andrews ${ }^{5}$, Janna L Harris ${ }^{2,3}$

1. University of Kansas School of Medicine, Kansas City, KS

2. Department of Anatomy and Cell Biology, KUMC, Kansas City, KS

3. Hoglund Biomedical Imaging Center, KUMC, Kansas City, KS

4. Department of Biostatistics, KUMC, Kansas City, KS

5. Department of Otolaryngology, University of lowa Carver College of Medicine, lowa City, IA

KEY WORDS: Traumatic brain injury, cerebral edema, MRI, sex differences

Corresponding author:

Janna L. Harris PhD

3901 Rainbow Blvd

University of Kansas Medical Center

Kansas City, KS 66160

This manuscript has been submitted as a preprint to bioRxiv (www.bioRxiv.org) under manuscript ID\# BIORXIV/2021/449932. 


\begin{abstract}
Traumatic brain injury (TBI) is one of the leading causes of death and disability worldwide. Cerebral edema following TBI is known to play a critical role in injury severity and prognosis. In the current study we used multimodal magnetic resonance imaging (MRI) to assess cerebral edema 24 hours after unilateral contusive TBI in male and female rats. We then directly quantified brain water content in the same subjects ex vivo. We found that in male rats, the injured cortex had higher brain water content and lower apparent diffusion coefficient (ADC) values compared with the contralateral side. Females did not show hemispheric differences for these measures. However, both males and females had similarly elevated $\mathrm{T}_{2}$ values in the injured cortex compared with the contralateral side. A strong correlation was observed between brain water content and $T_{2}$ values in the injured cortex in male rats, but not in females. These observations raise questions about the interpretation of radiological findings pertinent to edema in female TBI patients. A better mechanistic understanding of sex differences and similarities in the pathophysiology of post-traumatic edema is needed to help improve patient management and the development of effective treatment strategies for TBI in men and women.
\end{abstract}




\section{INTRODUCTION}

Traumatic brain injury (TBI) is a leading cause of death and disability in the United States ${ }^{1,2}$.

Post-traumatic edema is a critical element of TBI pathophysiology and is strongly related to poor patient outcomes $^{3-6}$. Cerebral edema and subsequent increases in intracranial pressure post-TBI are wellestablished prognostic factors for morbidity and mortality ${ }^{3,6}$.

Although women incur a significant number of TBIs, much is still unknown regarding differences in pathophysiology between men and women ${ }^{7,8}$. Historically, men have outnumbered women in clinical trials and most studies in animal models have been limited to male animals ${ }^{7,8}$. In TBI patients, the severity, type, and duration of symptoms appear to differ between men and women, although prospective and retrospective studies have not supported a significant association between sex and mortality after $\mathrm{TBI}^{9-13}$. In rodent $\mathrm{TBI}$ models, sex differences in brain damage and neurobehavioral recovery have long been established ${ }^{14}$. Steroid hormones such as estrogen and progesterone are thought to play a protective role against brain edema development and may help explain significant sex differences ${ }^{15-17}$.

In animal research, water content in the brain can be directly quantified via the "wet-dry" method, where freshly dissected tissue is weighed, desiccated, and weighed again to calculate the percent tissue water. Previous studies have used this approach to characterize cerebral edema in diffuse and focal TBI models ${ }^{18-21}$, but translation of findings requires alternative non-invasive methods. Magnetic resonance imaging (MRI) is routinely used for clinical management in stable TBI patients ${ }^{22-24}$. MRI is also increasingly being used in animal models to investigate TBI mechanisms, including cerebral edema. However, MRI methods have not been used to examine possible sex differences in edema after TBI. The goal of this study was to assess cerebral edema in male and female rats after moderate contusive TBI using multimodal MRI followed by direct quantification of brain water content. 


\section{MATERIALS AND METHODS}

\section{Animals}

Fifteen male and 15 female rats (F344; Charles River, Wilmington, MA, USA) were used in the study. Rats were 67-83 days old and weighed 157-229 g (male) and 112-152 g (female) at the time of surgery. Animals were housed in same-sex pairs on a 12-hour light-dark cycle with free access to food and water. All protocols were approved by the University of Kansas Medical Center Animal Care and Use Committee consistent with the standards of animal care in the United States Public Health Service Policy on the Humane Care and Use of Laboratory Animals. Each surgery cohort contained an equal number of male and female rats.

\section{Controlled Cortical Impact (CCl)}

$\mathrm{CCl}$ surgeries were carried out as we have previously described ${ }^{25-27}$. In brief, animals were anesthetized with isoflurane (4\% induction, 2\% maintenance in 2:1 Medical air:Oxygen). Body temperature was maintained with a heating pad. The head was immobilized in a stereotaxic frame, and the skin shaved and scrubbed with iodine and ethanol. Bupivacaine $(0.25 \%)$ was administered subcutaneously at the surgical site. Utilizing aseptic technique, a midline incision was made and the skull exposed. The circular craniectomy was formed by a $6 \mathrm{~mm}$ Michele trephine over the right sensorimotor cortex, lateral to bregma and centered between bregma and the temporal ridge. Moderate $\mathrm{CCl}$ was delivered with an impactor mounted to a stereotaxic manipulator (Leica; Saint Louis, MO; impactor tip diameter $=5 \mathrm{~mm} ;$ velocity $=5 \mathrm{~m} / \mathrm{s} ;$ depth $=2 \mathrm{~mm} ;$ contact time $=300 \mathrm{~ms} ;$ angle $=5^{\circ}$ from vertical). The incision was sutured closed and animals were transferred to a heated recovery cage. After recovery of locomotion, animals were returned to their home cages.

\section{Magnetic Resonance Imaging (MRI)}

MRI scans were performed approximately 24 hours after TBI (average $23.4 \pm 2.8$ hours) on a 9.4 Tesla system with a Varian INOVA console (Agilent Technologies, Santa Clara, CA). The system is 
equipped with a $12 \mathrm{~cm}$ gradient coil (40 G/cm, 250 s; Magnex Scientific, Abingdon, UK). A custommade quadrature surface radiofrequency coil, consisting of two geometrically decoupled 18mm loops, was placed on the animal's head to transmit and receive at $400 \mathrm{MHz}$.

During imaging, anesthesia was delivered via nosecone (1.5 - 3\% isoflurane in 2:1 Medical Air:Oxygen) to maintain a respiration rate of 40 - 80 cycles/minute. Respiration was monitored with a pressure pad (SA Instruments, Stony Brook, NY, USA). Animals were placed on a heating pad and body temperature was maintained at $37 \pm 1^{\circ} \mathrm{C}$ via feedback control (Cole Parmer, Veron Hills, IL, USA). Transverse and sagittal GEMS localization images were acquired to check the animal's positioning in the magnet $\left(\mathrm{FOV}_{\mathrm{ax}}=2.56 \times 2.56 \mathrm{~cm}^{2}, \mathrm{FOV}_{\mathrm{sag}}=5.12 \times 2.56 \mathrm{~cm}^{2}\right.$, matrix $=128 \times 128, \mathrm{TR} / \mathrm{TE}=90 \mathrm{~ms} / 2.8 \mathrm{~ms}$, slices $=9$, thickness $=1 \mathrm{~mm}$ ). High-resolution $\mathrm{T}_{2}$-weighted images were acquired using a RARE sequence $\left(\mathrm{FOV}=2.56 \times 2.56 \mathrm{~cm}^{2}\right.$, matrix $=256 \times 256, \mathrm{TR} / \mathrm{TE}=4000 / 72 \mathrm{~ms}$, averages $=2$, thickness $=1 \mathrm{~mm}$, echo train length $=8$, echo spacing $=18 \mathrm{~ms}$, total acquisition time $\sim 4$ minutes).

Diffusion weighted imaging (DWI) was performed using a standard mono-polar diffusion weighted spin echo sequence $\left(F O V=2.56 \times 2.56 \mathrm{~cm}^{2}\right.$, matrix $=128 \times 128, T R / T E=1500 / 26 \mathrm{~ms}$, gradients applied along readout direction, $b=50,500,1000 \mathrm{~s} / \mathrm{mm}^{2}$, averages $=1$, slices $=9$, thickness $=0.8 \mathrm{~mm}$ with a $0.2 \mathrm{~mm}$ gap, total acquisition time 9 minutes 40 seconds). Apparent diffusion coefficient (ADC) values were calculated for each voxel in MATLAB (Mathworks Inc., Natick, MA, USA) from a 2-parameter exponential fit of the $b$ values.

For mapping $T_{2}$ weighted images, a series of multi-slice spin echo acquisitions were performed $\left(\mathrm{FOV}=2.56 \times 2.56 \mathrm{~cm}^{2}\right.$, matrix $=128 \times 128, \mathrm{TR}=3 \mathrm{~s}, \mathrm{TE}=20,30,50,75,100,150 \mathrm{~ms}$, averages $=2$, slices $=9$, thickness $=0.8 \mathrm{~mm}$ with a $0.2 \mathrm{~mm}$ gap, acquisition time $=6$ minutes 25 seconds for each $\mathrm{TE})$.

$T_{2}$ values were calculated for each voxel in MATLAB from a 2-parameter exponential fit of the TE values. The DWI and $\mathrm{T}_{2}$ maps were acquired with identical slice positions, FOV, and spatial resolution. 


\section{Brain water content}

Immediately following MRI, rats received an overdose of isoflurane and were euthanized via decapitation. Brain tissue was rapidly extracted from the skull, placed in a coronal slicing matrix, and a $10 \mathrm{~mm}$ block was cut beginning $\sim 1 \mathrm{~mm}$ rostral to the cortical injury extending caudally (Fig. 1A). The block was removed, cut in half horizontally to separate dorsal from ventral structures, then cut in half vertically at the midline (Fig. 1B). The dorsal brain samples from the left (contralateral to TBI) and right (ipsilateral to TBI) hemispheres were used for wet-dry analyses. Each sample was immediately weighed (Mettler Toledo AE100 Scale, Columbus, OH, USA) and values were recorded as the wet weight. The samples were then placed in a laboratory oven (Grieve Laboratory Oven Model L R-271C, Round Lake, IL, USA) at $100{ }^{\circ} \mathrm{C}$. Dry weights were recorded after 24,48 and 72 hours and the lowest dry weight was used in water content calculation; for most subjects this was at 72 hours. Water content was calculated using the formula: [wet weight (g) - dry weight (g)] / [wet weight (g)] x 100.

\section{MRI analysis}

Regions of interest (ROIs) were drawn over the ipsilateral and contralateral cortex for each subject using MIPAV software. ROIs were drawn on three sequential diffusion weighted images $(b=50$ $\mathrm{s} / \mathrm{mm}^{2}$ ) encompassing the center of the injury (centered at bregma). First a vertical line was drawn at the midline, and from a point marked at the base of the brain a second line was drawn at a 45-degree angle. The ROI was completed by connecting the points where these lines crossed the cortex, following the dorsal surface of the brain and the corpus callosum. After the ROI was drawn for the ipsilateral cortex, it was flipped 180 degrees across the vertical midline and manually adjusted to fit the contralateral hemisphere. The same ROIs, generated by a single experimenter, were used for analysis of DWI and $T_{2}$ images. 


\section{Statistical analysis}

Descriptive data are reported as mean \pm standard error. We used mixed-effects ANOVA with sex as the between-subjects factor and hemisphere as the within-subjects factor, followed by paired ttests to compare hemispheres within each sex. Bonferroni adjustment was applied for each outcome measure to control for multiple comparisons. Correlations between MRI parameters and brain water content were analyzed using the Spearman test. All tests were two-sided and performed with $\mathrm{R}$ software ${ }^{28}$. Statistical significance was defined as $p<0.05$.

\section{Subject exclusions and MRI quality screening}

One female rat died during imaging and was excluded from the study. Tissue water measurements were excluded from 4 rats ( 1 male, 3 female) due to data collection error. Quality assessments of MRI data were performed by a blinded screener. For DWI, screening led to exclusion of 2 males and 2 females due to motion artifact. For the $T_{2}$ images, 2 males and 1 female were excluded due to data corruption. Subjects with partial data (e.g. successful $T_{2}$ but not DWI) were included in the analysis.

\section{RESULTS}

\section{Brain water content}

Brain water measurements showed a main effect of hemisphere and a significant interaction between hemisphere and $\operatorname{sex}(F(1,23)=7.575, p=0.011)$ indicating that the effect of TBI was different between males and females. Follow-up testing showed significantly higher brain water in the ipsilateral hemisphere compared to contralateral in males $(83.43 \pm 1.05$ ipsi vs. $82.92 \pm 1.04$ contra; $p=0.0016)$ but no difference in females ( $83.82 \pm 1.03$ ipsi vs. $83.86 \pm 1.07$ contra; Fig. 2). 


\section{Diffusion weighted imaging}

ADC measurements from an ROI centered on the injured cortex and a control ROI on the contralateral side (Fig. 3A) showed no main effect of hemisphere or sex, and a trend toward interaction between hemisphere and sex that did not reach significance $(F(1,18)=3.338, p=0.084)$. Although there were no main effects, since previous studies generally restricted to males have found reduced ADC

acutely after $\mathrm{TBI}^{29-32}$, we separately explored effects of injury on $\mathrm{ADC}$ within each group. Paired t-tests found male rats had lower $A D C$ in the injured cortex than on the contralateral side $(6.2 \mathrm{E}-04 \pm 8.63 \mathrm{E}-06$ ipsi vs. $6.60 \mathrm{E}-04 \pm 1.25 \mathrm{E}-05$ contra, $p=0.019$; Fig. 3B) while female rats showed no difference between ipsilateral and contralateral ADC (6.36E-04 $\pm 1.98 \mathrm{E}-05$ ipsi vs. $6.13 \mathrm{E}-04 \pm 2.15 \mathrm{E}-05$ contra; Fig. 3B).

\section{$T_{2}$-weighted image mapping}

$T_{2}$ values in the injured cortex showed a main effect of hemisphere $(F(1,18)=54.014, p<0.0001)$. There was no main effect of sex and no interaction between sex and hemisphere. Follow-up testing showed significantly higher $\mathrm{T}_{2}$ in the ipsilateral ROI compared to the contralateral side in males (41.85 \pm 0.68 ipsi vs. $38.38 \pm 0.16$ contra, $p=0.0001)$ and in females (41.56 \pm 0.47 ipsi vs. $38.36 \pm 0.31$ contra, $p<$ $0.0001)$.

\section{Correlation between brain water content and imaging measures}

In the injured hemisphere of male rats, brain water content trended toward a negative correlation with $A D C$ values, but this did not reach significance $(r=-0.44, p=0.15 ;$ Fig. 3). In males after TBI there was a strong positive correlation between brain water and $\mathrm{T}_{2}$ values $(r=0.73, p=0.007)$. By contrast, in female rats the brain water content in the injured hemisphere was not correlated with either ADC values $(r=0.30, p=0.43)$ or with $T_{2}$ values $(r=0.01, p=0.96)$. 


\section{DISCUSSION}

Sex differences in TBI damage and subsequent functional recovery have long been observed. However, the mechanisms underlying this observation have not been well characterized. This study used multimodal MRI and brain water measurements to assess cerebral edema 24 hours after contusive TBI in male and female rats. At this acute time point, we found consistent evidence of post-traumatic edema in males but more mixed results in females. In male rats, the hemisphere that received a direct cortical contusion had significantly higher brain water content, lower ADC, and higher $\mathrm{T}_{2}$ values than the contralateral side, while in females the injured hemisphere showed only elevated $T_{2}$.

Classically, cerebral edema has been categorized as either vasogenic or cytotoxic in origin. More recently it has been recognized that this distinction may be somewhat arbitrary since the molecular mechanisms of both processes are highly inter-related ${ }^{33}$. Vasogenic edema arises from direct disruption of the blood brain barrier and leaking of solute-laden fluid from the blood into the brain interstitial space. Cytotoxic edema results from disruptions to cell membrane ion channels causing ion-driven movement of water into cells and a relative shrinkage of the extracellular compartment. Quantitative DWI and $T_{2}$ mapping have each been used as imaging biomarkers of cerebral edema ${ }^{30,34-37}$. The ADC calculated from DWI is a measure of water diffusion within the target tissue, which is influenced by the relative balance of water in the intracellular versus the extracellular compartment. Thus, elevated intracellular water (i.e. cytotoxic edema) tends to lower the ADC, while elevated extracellular water (vasogenic edema) tends to increase $A D C^{31,37-40}$. By contrast, $T_{2}$ mapping measures the transverse relaxation time of protons and is sensitive to the total water content in the tissue regardless of cellular compartment.

In male rats we found lower $A D C$ and higher $T_{2}$ values in the injured cortex, confirming a predominantly intracellular edema as previously reported ${ }^{29,31,37}$. In female rats, we found no difference in ADC values between hemispheres, but elevated $T_{2}$ in the injured cortex. One interpretation is that $T_{2}$ 
mapping is a more sensitive measure of cerebral edema than diffusion weighted imaging. If this is the case, it remains unclear why female rats showed elevated $T_{2}$ in the injured cortex but not elevated brain water content. This difference could result from the slightly different regions sampled or from differing sensitivities of the two methods. Alternatively, the lack of hemispheric difference in ADC in female rats could reflect a more heterogeneous manifestation of edema; indeed individual female rats showed a wide range of $A D C$ responses to $T B I$ including decrease (reflecting primarily intracellular edema), increase (primarily extracellular edema), and no change from the contralateral side (reflecting either no edema, or potentially a balanced mix of intracellular and extracellular edema). The reason for this variability in females remains to be determined, but certainly hormonal cycle stage is a strong candidate for investigation.

In this initial study we did not control for hormonal status in female rats, since in the real-world women may sustain TBI at any time in their cycle. A growing body of research indicates that estrogen and progesterone may attenuate several aspects of TBI pathophysiology, including edema ${ }^{16,17,41-45}$. It is possible that differing sex hormone levels associated with cycle stage contributed to the greater variability of $A D C$ and $T_{2}$ values we observed in female rats compared with males. However, the variability of brain water measurements was similar in males and female groups. This underscores the growing recognition that hormonal effects on TBI outcomes are complex and may depend on the particular outcome measure used, the time point, and characteristics of the injury ${ }^{7,8,16,46-49}$.

We measured cerebral edema 24 hours post injury, a time point that corresponds to maximal edema after $\mathrm{CCl}$ in adult male rats $20,21,29,50$. Since the development of edema after brain trauma is a dynamic process, the timing of which is likely to be affected by the severity and type of injury, results from single time point studies should be interpreted with caution. A possible interpretation of our results is that females develop less severe edema than males after identical TBI procedures; an alternative explanation might be that the time course of edema development differs in males versus 
females. Indeed, in a time course study of diffuse TBI, O'Connor et al. reported that female rats had more severe edema than males at $24 \mathrm{~h}$, and also had less edema than males at earlier and later timepoints ${ }^{51}$. To date, sex differences in the time course of edema have not been investigated after focal TBI, and longitudinal studies that include both sexes remain an important area for future research.

The surgeries and imaging procedures in this study were performed under isoflurane anesthesia, with the dose of isoflurane in each animal adjusted during the course of each procedure based on physiological parameters. In order to determine whether different anesthesia doses might have contributed to the sex differences we observed, we reviewed our study records to calculate the anesthesia duration and the cumulative anesthesia dose (percent isoflurane $x$ time) for each animal. We found no difference between males and females in either metric (Supplemental Table S1). Previous studies have reported that isoflurane can worsen post-traumatic edema, but these were conducted exclusively in male animals ${ }^{52-54}$. The effect of isoflurane on cerebral edema in females is unknown, but if it is similar to males then we would speculate that in our study the same average dose administered to males and females would affect both groups equally. The requirement for anesthesia is an inherent limitation of invasive studies in animal models, but future studies can help address this by intentionally matching the isoflurane dose and duration between experimental and control groups, tracking isoflurane dose for use as a covariate, and/or considering alternative inhaled or injectable anesthetic agents $^{29,50,51,55}$.

Translational neuroimaging studies in animals allow for direct comparison between non-invasive MRI measures and invasive assays to confirm pathophysiological mechanisms. We found that ADC and $T_{2}$ values-imaging measures that have traditionally been used to make inferences about cerebral edema-were associated with measured brain water content as predicted in male rats, but not in females. The reason for this is not currently clear, but the observation raises important questions about clinical interpretation of radiological findings in female TBI patients. Due to a historic focus on males in 
TBI research, much remains unknown about sex differences in TBI pathophysiology. The lack of data currently available on the time course and molecular mechanisms of cerebral edema in females needs to be addressed. A better understanding of the differences and similarities between sexes will help improve patient management and the development of effective treatment strategies.

\section{ACKNOWLEDGEMENTS}

The authors acknowledge the helpful contributions of Sadie Land to the preparation and formatting of data for publication.

\section{AUTHOR CONTRIBUTION STATEMENT}

J Harris and HM conceptualized and designed the study; J Harris performed surgeries; HM, SC, and PK performed the MRI and brain water experiments; HM, SC, PK, J Hu completed data processing and analysis; J Harris, J Hu, HM, BA contributed to data interpretation and manuscript preparation.

\section{AUTHOR DISCLOSURE STATEMENT}

The authors have no competing financial interests.

\section{FUNDING}

This work was supported by the National Institutes of Health [National Institute on Aging grant number R21AG058052 and National Center for Advancing Translational Sciences grant number TL1TR002368]. 


\section{REFERENCES}

1. Faul M, Coronado V. Epidemiology of traumatic brain injury. Handbook of clinical neurology. 2015;127:3-13. doi:10.1016/b978-0-444-52892-6.00001-5

2. Daugherty J, Waltzman D, Sarmiento K, Xu L. Traumatic Brain Injury-Related Deaths by Race/Ethnicity, Sex, Intent, and Mechanism of Injury - United States, 2000-2017. MMWR Morb Mortal Wkly Rep. Nov 22 2019;68(46):1050-1056. doi:10.15585/mmwr.mm6846a2

3. Stocchetti N, Maas Al. Traumatic intracranial hypertension. N Engl J Med. May 29 2014;370(22):2121-30. doi:10.1056/NEJMra1208708

4. Tucker B, Aston J, Dines M, et al. Early Brain Edema is a Predictor of In-Hospital Mortality in Traumatic Brain Injury. J Emerg Med. 2017;53(1):18-29.

doi:10.1016/j.jemermed.2017.02.010

5. Winkler EA, Minter D, Yue JK, Manley GT. Cerebral Edema in Traumatic Brain Injury: Pathophysiology and Prospective Therapeutic Targets. Neurosurgery clinics of North America. 2016;27(4):473-488. doi:10.1016/j.nec.2016.05.008

6. Marmarou A. The pathophysiology of brain edema and elevated intracranial pressure. Cleve Clin J Med. Jan 2004;71 Suppl 1:S6-8. doi:10.3949/ccjm.71.suppl_1.s6

7. Gupte R, Brooks W, Vukas R, Pierce J, Harris J. Sex Differences in Traumatic Brain Injury: What We Know and What We Should Know. Journal of neurotrauma. 2019;36(22):3063-3091. doi:10.1089/neu.2018.6171

8. Rubin TG, Lipton ML. Sex Differences in Animal Models of Traumatic Brain Injury. J Exp Neurosci. 2019;13:1179069519844020. doi:10.1177/1179069519844020

9. Yeung JH, Mikocka-Walus AA, Cameron PA, et al. Protection from traumatic brain injury in hormonally active women vs men of a similar age: a retrospective international study. Arch Surg. Apr 2011;146(4):436-42. doi:10.1001/archsurg.2011.46

10. Renner $\mathrm{C}$, Hummelsheim $\mathrm{H}$, Kopczak $\mathrm{A}$, et al. The influence of gender on the injury severity, course and outcome of traumatic brain injury. Brain Inj. 2012;26(11):1360-71. doi:10.3109/02699052.2012.667592

11. Preiss-Farzanegan SJ, Chapman B, Wong TM, Wu J, Bazarian JJ. The relationship between gender and postconcussion symptoms after sport-related mild traumatic brain injury. Pm r. Mar 2009;1(3):245-53. doi:10.1016/j.pmrj.2009.01.011

12. Mathias JL, Wheaton P. Contribution of brain or biological reserve and cognitive or neural reserve to outcome after TBI: A meta-analysis (prior to 2015). Neurosci Biobehav Rev. Aug 2015;55:573-93. doi:10.1016/j.neubiorev.2015.06.001

13. Levin HS, Temkin NR, Barber J, et al. Association of Sex and Age With Mild Traumatic Brain Injury-Related Symptoms: A TRACK-TBI Study. JAMA Netw Open. Apr 1 2021;4(4):e213046. doi:10.1001/jamanetworkopen.2021.3046

14. Stein DG. Sex differences in brain damage and recovery of function: experimental and clinical findings. Prog Brain Res. 2007;161:339-51. doi:10.1016/s0079-6123(06)61024-8

15. Hajmohammadi M, Khaksari M, Soltani Z, Shahrokhi N, Najafipour H, Abbasi R. The Effect of Candesartan Alone and Its Combination With Estrogen on Post-traumatic Brain Injury Outcomes in Female Rats. Front Neurosci. 2019;13:1043-1043. doi:10.3389/fnins.2019.01043

16. Maghool F, Khaksari M, Siahposht Khachki A. Differences in brain edema and intracranial pressure following traumatic brain injury across the estrous cycle: involvement of 
female sex steroid hormones. Brain research. Feb 25 2013;1497:61-72.

doi:10.1016/j.brainres.2012.12.014

17. Roof RL, Duvdevani R, Stein DG. Gender influences outcome of brain injury: progesterone plays a protective role. Brain research. Apr 2 1993;607(1-2):333-6. doi:10.1016/0006-8993(93)91526-x

18. Genét GF, Bentzer P, Ostrowski SR, Johansson PI. Resuscitation with Pooled and Pathogen-Reduced Plasma Attenuates the Increase in Brain Water Content following Traumatic Brain Injury and Hemorrhagic Shock in Rats. Journal of neurotrauma. 2017;34(5):1054-1062. doi:10.1089/neu.2016.4574

19. Sebastiani A, Hirnet T, Jahn-Eimermacher A, Thal SC. Comparison of speed-vacuum method and heat-drying method to measure brain water content of small brain samples. $J$ Neurosci Methods. 2017;276:73-78. doi:10.1016/j.jneumeth.2016.11.012

20. Markgraf CG, Clifton GL, Moody MR. Treatment window for hypothermia in brain injury. J Neurosurg. Dec 2001;95(6):979-83. doi:10.3171/jns.2001.95.6.0979

21. Schuhmann MU, Stiller D, Skardelly M, et al. Determination of contusion and oedema volume by MRI corresponds to changes of brain water content following controlled cortical impact injury. Acta Neurochir Suppl. 2002;81:213-5.

22. Smith LGF, Milliron E, Ho ML, et al. Advanced neuroimaging in traumatic brain injury: an overview. Neurosurg Focus. Dec 1 2019;47(6):E17. doi:10.3171/2019.9.Focus19652

23. Wintermark M, Sanelli PC, Anzai Y, Tsiouris AJ, Whitlow CT. Imaging evidence and recommendations for traumatic brain injury: conventional neuroimaging techniques. J Am Coll Radiol. Feb 2015;12(2):e1-14. doi:10.1016/j.jacr.2014.10.014

24. Davis T, Ings A. Head injury: triage, assessment, investigation and early management of head injury in children, young people and adults (NICE guideline CG 176). Archives of disease in childhood - Education \&amp; practice edition. 2015;100(2):97-100. doi:10.1136/archdischild2014-306797

25. Pierce JD, Gupte $R$, Thimmesch A, et al. Ubiquinol treatment for TBI in male rats: Effects on mitochondrial integrity, injury severity, and neurometabolism. Journal of neuroscience research. 2018;96(6):1080-1092. doi:10.1002/jnr.24210

26. Gupte R, Christian S, Keselman P, Habiger J, Brooks WM, Harris JL. Evaluation of taurine neuroprotection in aged rats with traumatic brain injury. Brain Imaging Behav. 2019;13(2):461471. doi:10.1007/s11682-018-9865-5

27. Harris JL, Yeh HW, Choi IY, et al. Altered neurochemical profile after traumatic brain injury: (1)H-MRS biomarkers of pathological mechanisms. J Cereb Blood Flow Metab. Dec 2012;32(12):2122-34. doi:10.1038/jcbfm.2012.114

28. $R$ : A language and environment for statistical computing. $\mathrm{R}$ Foundation for Statistical Computing; 2021. https://www.R-project.org/.

29. Unterberg AW, Stroop R, Thomale UW, Kiening KL, Päuser S, Vollmann W. Characterisation of brain edema following "controlled cortical impact injury" in rats. Acta Neurochir Suppl. 1997;70:106-8. doi:10.1007/978-3-7091-6837-0_33

30. Li YH, Wang JB, Li MH, Li WB, Wang D. Quantification of brain edema and hemorrhage by MRI after experimental traumatic brain injury in rabbits predicts subsequent functional outcome. Neurol Sci. Aug 2012;33(4):731-40. doi:10.1007/s10072-011-0768-0 
31. Barzó P, Marmarou A, Fatouros P, Hayasaki K, Corwin F. Contribution of vasogenic and cellular edema to traumatic brain swelling measured by diffusion-weighted imaging. Journal of neurosurgery. 1997;87(6):900-907. doi:10.3171/jns.1997.87.6.0900

32. Stroop R, Thomale UW, Päuser $\mathrm{S}$, et al. Magnetic resonance imaging studies with cluster algorithm for characterization of brain edema after controlled cortical impact injury (CCII). Acta Neurochir Suppl. 1998;71:303-5. doi:10.1007/978-3-7091-6475-4_88

33. Jha RM, Kochanek PM, Simard JM. Pathophysiology and treatment of cerebral edema in traumatic brain injury. Neuropharmacology. Feb 2019;145(Pt B):230-246.

doi:10.1016/j.neuropharm.2018.08.004

34. Kharatishvili I, Sierra A, Immonen RJ, Gröhn OH, Pitkänen A. Quantitative T2 mapping as a potential marker for the initial assessment of the severity of damage after traumatic brain injury in rat. Experimental neurology. May 2009;217(1):154-64.

doi:10.1016/j.expneurol.2009.01.026

35. Maegele M, Stuermer EK, Hoeffgen A, et al. Multimodal MR imaging of acute and subacute experimental traumatic brain injury: Time course and correlation with cerebral energy metabolites. Acta radiologica short reports. Jan 2015;4(1):2047981614555142.

doi:10.1177/2047981614555142

36. Jullienne A, Hamer M, Haddad E, et al. Acute intranasal osteopontin treatment in male rats following $T B \mathrm{~B}$ increases the number of activated microglia but does not alter lesion characteristics. Journal of neuroscience research. Jan 2020;98(1):141-154. doi:10.1002/jnr.24405

37. Ren H, Lu H. Dynamic features of brain edema in rat models of traumatic brain injury. Neuroreport. Jun 12 2019;30(9):605-611. doi:10.1097/WNR.0000000000001213

38. Sevick RJ, Kanda F, Mintorovitch J, et al. Cytotoxic brain edema: assessment with diffusion-weighted MR imaging. Radiology. 1992;185(3):687-690.

doi:10.1148/radiology.185.3.1438745

39. Wei XE, Zhang YZ, Li YH, Li MH, Li WB. Dynamics of rabbit brain edema in focal lesion and perilesion area after traumatic brain injury: a MRI study. Journal of neurotrauma. Sep 20 2012;29(14):2413-20. doi:10.1089/neu.2010.1510

40. Van Putten HP, Bouwhuis MG, Muizelaar JP, Lyeth BG, Berman RF. Diffusion-weighted imaging of edema following traumatic brain injury in rats: effects of secondary hypoxia. Journal of neurotrauma. 2005;22(8):857-872. doi:10.1089/neu.2005.22.857

41. Kim H, Yu T, Cam-Etoz B, van Groen T, Hubbard WJ, Chaudry IH. Treatment of traumatic brain injury with $17 \alpha$-ethinylestradiol-3-sulfate in a rat model. Journal of neurosurgery. Jul 2017;127(1):23-31. doi:10.3171/2016.7.Jns161263

42. Naderi V, Khaksari M, Abbasi R, Maghool F. Estrogen provides neuroprotection against brain edema and blood brain barrier disruption through both estrogen receptors $\alpha$ and $\beta$ following traumatic brain injury. Iran J Basic Med Sci. Feb 2015;18(2):138-44.

43. Shahrokhi N, Haddad MK, Joukar S, Shabani M, Keshavarzi Z, Shahozehi B. Neuroprotective antioxidant effect of sex steroid hormones in traumatic brain injury. Pak $J$ Pharm Sci. Jan 2012;25(1):219-25.

44. Shahrokhi N, Khaksari M, Soltani Z, Mahmoodi M, Nakhaee N. Effect of sex steroid hormones on brain edema, intracranial pressure, and neurologic outcomes after traumatic brain injury. Can J Physiol Pharmacol. Apr 2010;88(4):414-21. doi:10.1139/y09-126 
45. Geddes RI, Peterson BL, Stein DG, Sayeed I. Progesterone Treatment Shows Benefit in Female Rats in a Pediatric Model of Controlled Cortical Impact Injury. PLoS One. 2016;11(1):e0146419. doi:10.1371/journal.pone.0146419

46. Späni CB, Braun DJ, Van Eldik L. Sex-related responses after traumatic brain injury: Considerations for preclinical modeling. Front Neuroendocrinol. Jul 2018;50:52-66. doi:10.1016/j.yfrne.2018.03.006

47. Wagner AK, Bayir H, Ren D, Puccio A, Zafonte RD, Kochanek PM. Relationships between cerebrospinal fluid markers of excitotoxicity, ischemia, and oxidative damage after severe TBI: the impact of gender, age, and hypothermia. J Neurotrauma. Feb 2004;21(2):125-36. doi:10.1089/089771504322778596

48. Mihalik JP, Ondrak KS, Guskiewicz KM, McMurray RG. The effects of menstrual cycle phase on clinical measures of concussion in healthy college-aged females. J Sci Med Sport. 2009;12(3):383-387. doi:10.1016/j.jsams.2008.05.003

49. Clevenger AC, Kim H, Salcedo E, et al. Endogenous Sex Steroids Dampen Neuroinflammation and Improve Outcome of Traumatic Brain Injury in Mice. J Mol Neurosci. 2018;64(3):410-420. doi:10.1007/s12031-018-1038-x

50. Roof RL, Duvdevani R, Heyburn JW, Stein DG. Progesterone rapidly decreases brain edema: treatment delayed up to 24 hours is still effective. Experimental neurology. Apr 1996;138(2):246-51. doi:10.1006/exnr.1996.0063

51. O'Connor CA, Cernak I, Vink R. The temporal profile of edema formation differs between male and female rats following diffuse traumatic brain injury. Acta neurochirurgica Supplement. 2006;96:121-124. doi:10.1007/3-211-30714-1_27

52. Stover JF, Kroppenstedt SN, Thomale UW, Kempski OS, Unterberg AW. Isoflurane doubles plasma glutamate and increases posttraumatic brain edema. Acta Neurochir Suppl. 2000;76:375-8. doi:10.1007/978-3-7091-6346-7_78

53. Stover JF, Sakowitz OW, Kroppenstedt SN, et al. Differential effects of prolonged isoflurane anesthesia on plasma, extracellular, and CSF glutamate, neuronal activity, 125IMk801 NMDA receptor binding, and brain edema in traumatic brain-injured rats. Acta Neurochir (Wien). Aug 2004;146(8):819-30. doi:10.1007/s00701-004-0281-9

54. Thal SC, Luh C, Schaible EV, et al. Volatile anesthetics influence blood-brain barrier integrity by modulation of tight junction protein expression in traumatic brain injury. PLoS One. 2012;7(12):e50752. doi:10.1371/journal.pone.0050752

55. O'Connor CA, Cernak I, Vink R. Interaction between anesthesia, gender, and functional outcome task following diffuse traumatic brain injury in rats. Journal of neurotrauma. Jun 2003;20(6):533-41. doi:10.1089/089771503767168465 


\section{Legends}

Figure 1. Brain injury location and regions dissected for brain water content analysis. A) dorsal view of the rat brain. The circle depicts the site of craniectomy and cortical impact. Using a coronal slicing matrix, a $10 \mathrm{~mm}$ thick section of brain was dissected beginning $\sim 1 \mathrm{~mm}$ anterior to the cortical injury and extending caudally. (B) The $10 \mathrm{~mm}$ section was further dissected with a horizontal slice aligned with the bottom of the corpus callosum as shown, and a vertical slice at the midline to separate the left (contralateral to TBI) and right (ipsilateral to TBI) sides. The dorsal brain samples from each side were used for analysis of brain water content.

Figure 2. Brain water content after TBI in male and female rats. Plot shows the calculated percent tissue water with lines connecting the contralateral and ipsilateral measures in each subject. In male rats, a paired t-test showed higher brain water in the ipsilateral hemisphere compared to contralateral $(p=0.0016)$. In female rats, there was no significant difference in brain water between hemispheres.

Figure 3. Magnetic resonance imaging measures of cerebral edema after TBI in male and female rats.

(A) Regions of interest (ROI) for analysis are shown on three sequential diffusion weighted images encompassing the center of the injury in a male rat 24 hours after controlled cortical impact. Contralateral $\mathrm{ROI}=$ grey outline, ipsilateral $\mathrm{ROI}$ = black outline. $(\mathrm{B})$ Plots show mean ROI values, with lines connecting the contralateral and ipsilateral measures in each subject. In male rats, a paired t-test showed lower apparent diffusion coefficient $(A D C)$ values ipsilateral to injury compared with the contralateral side $(p=0.019)$. In female rats, there was no significant difference between ipsilateral and contralateral $A D C$. By contrast, $T_{2}$ values were higher in the ipsilateral ROI compared with the contralateral side in both males $(p=0.0001)$ and females $(p<0.0001)$. 
bioRxiv preprint doi: https://doi.org/10.1101/2021.06.25.449932; this version posted September 10, 2021. The copyright holder for this preprint

(which was not certified by peer review) is the author/funder, who has granted bioRxiv a license to display the preprint in perpetuity. It is made available under aCC-BY-NC-ND 4.0 International license.

Figure 4. Relationship between brain water content and MRI measures of cerebral edema in male and

female rats. In the injured hemisphere of male rats 24 hours after $\mathrm{TBI}$, there was a trend toward negative association between brain water content and ADC values that did not reach significance $(r=-$ $0.44, p=0.15)$. Brain water content in males was strongly correlated with $T_{2}$ values in the cortex ipsilateral to injury $(r=0.73, p=0.007)$. By contrast, water content in the injured hemisphere of female rats was not correlated with $A D C(r=0.30)$ or with $T_{2}$ values $(r=0.01)$. Note that animals with partial data were included in the study (e.g. successful $T_{2}$ but not DWI scan, see details in "Subject exclusions and MRI quality screening"). 
Figure 1

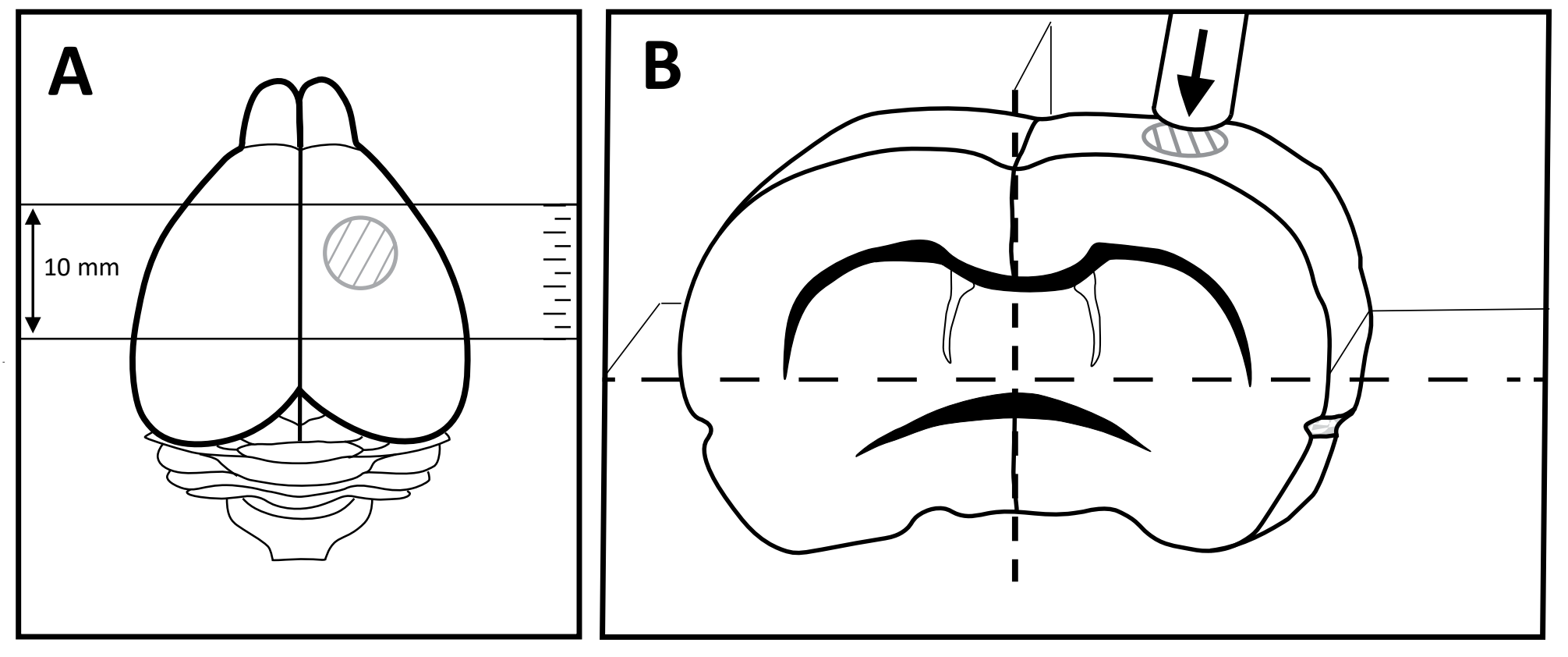


bioRxiv preprint doi: https://doi.org/10.1101/2021.06.25.449932; this version posted September 10, 2021. The copyright holder for this preprint (which was not certified by peer review) is the author/funder, who has granted bioRxiv a license to display the preprint in perpetuity. It is made Figure 2

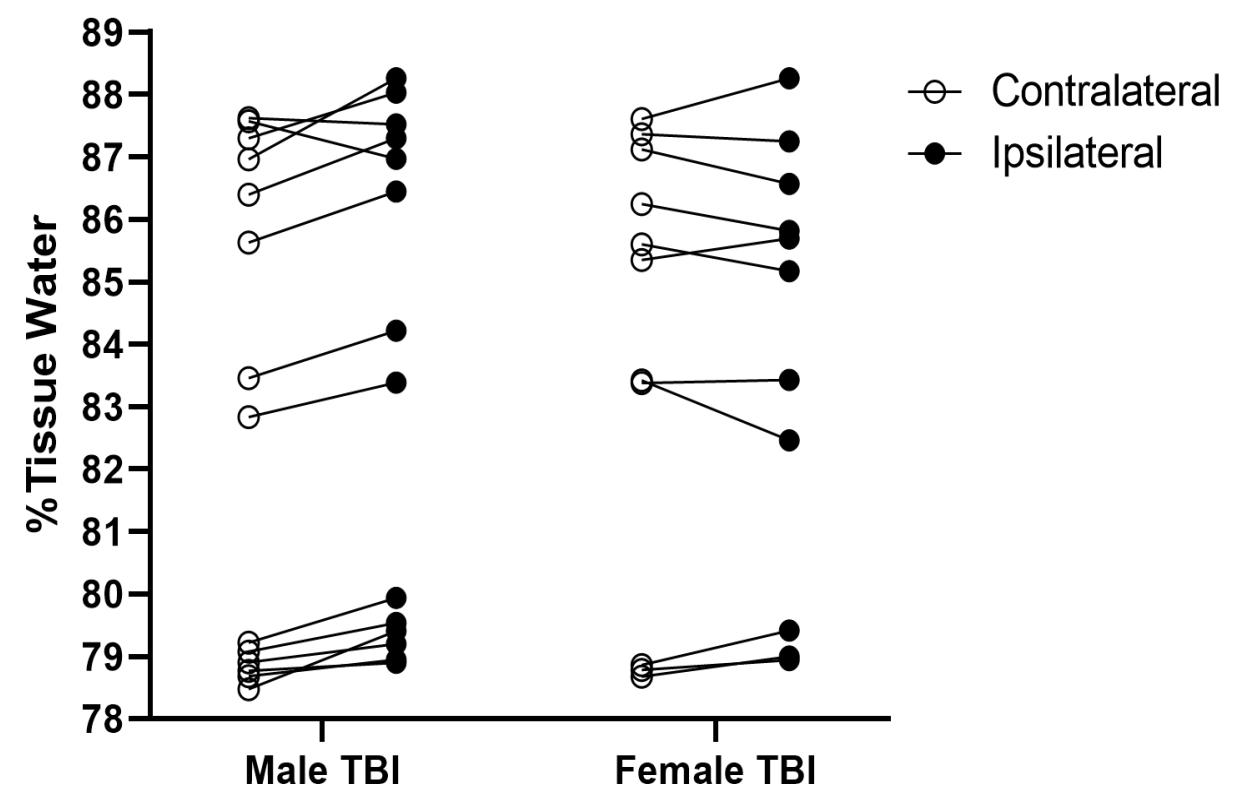


bioRxiv preprint doi: https://doi.org/10.1101/2021.06.25.449932; this version posted September 10, 2021. The copyright holder for this preprint (which was not certified by peer review) is the author/funder, who has granted bioRxiv a license to display the preprint in perpetuity. It is made Figure 3 available under aCC-BY-NC-ND 4.0 International license.
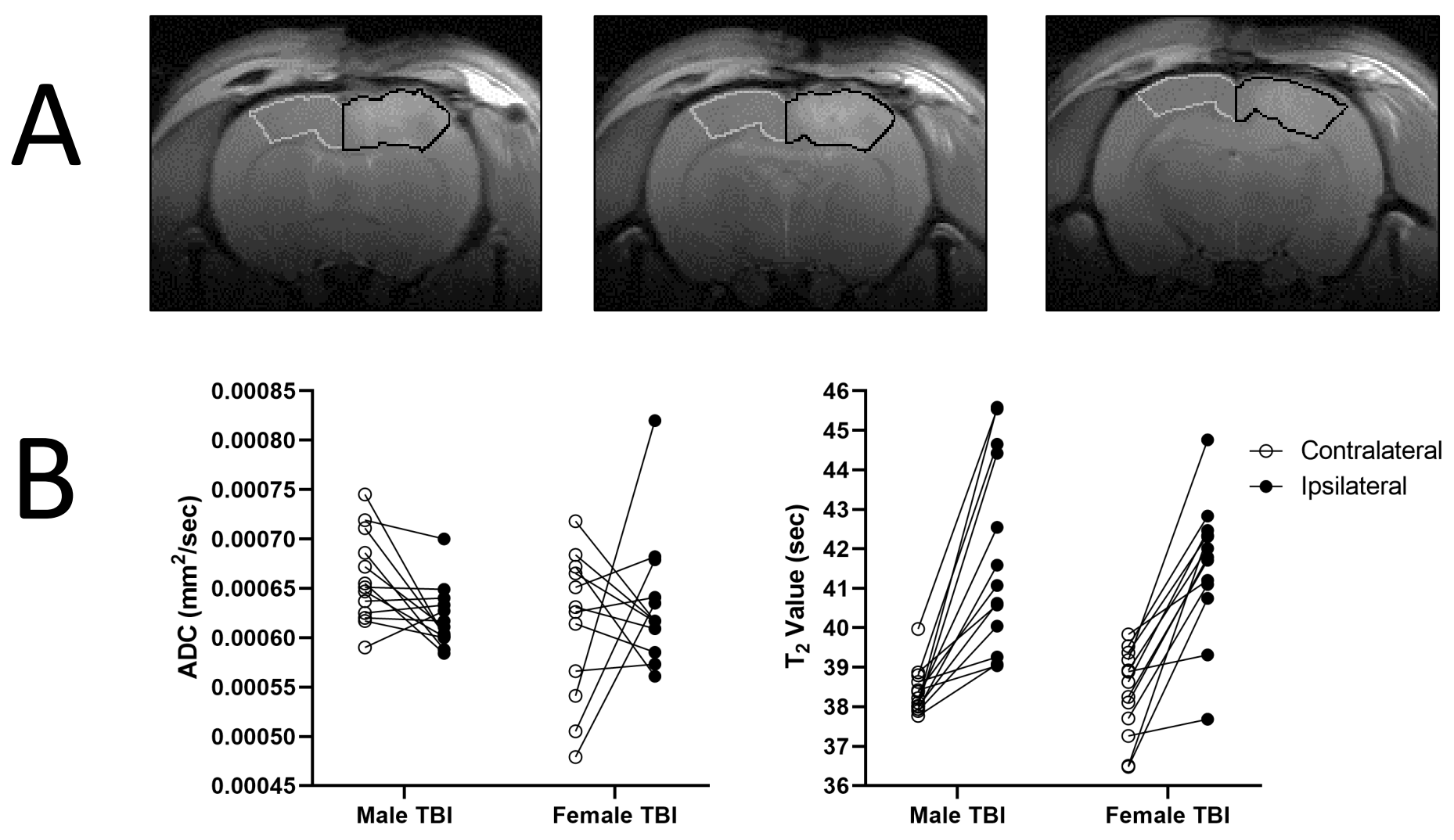
Figure 4
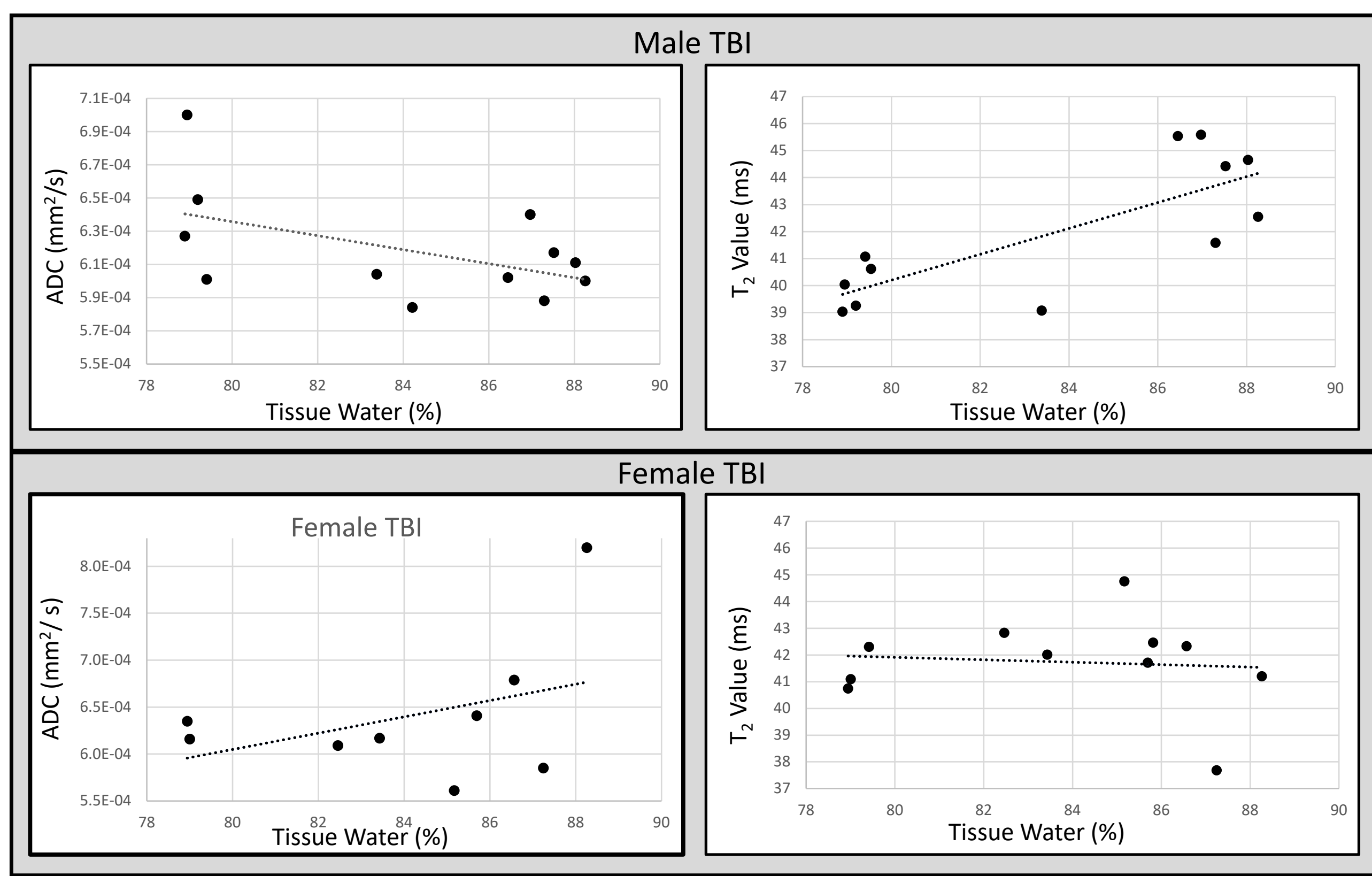